\title{
Effects of progesterone on the reproductive physiology in
}

\section{zebrafish}

\author{
Chunyun Zhong, Kewen Xiong, Xin Wang \\ Department of Environmental Toxicity, Third Hospital of Shanxi University
}

Keywords: Progestin; Progesterone; Reproduction; Endocrine disruption

\begin{abstract}
Recent studies have investigated that the synthetic progestins may lead to health issues to the aquatic organisms. Progesterone is a steroidal progestin and has been used as a contraceptive drug, which is detected in the aquatic ecosystem. However, the potential effects of progesterone on the fish reproduction are largely unclear. Here, we tested the effects of progesterone on the fish reproductive and endocrine systems. Adult zebrafish were exposed to progesterone for 10 days at environmental concentrations. The production of eggs was reduced in the exposed fish, and the circulating concentrations of estradiol (E2) and testosterone (T) in female fish or 11-keto testosterone (11-KT) in male fish were significantly diminished. Our results suggested that progesterone may cause adverse health effects on fish by disrupting the endocrine system, and short-term exposure to progesterone could overt affect the fish reproduction.
\end{abstract}




\section{Introduction}

Many studies reported the endocrine-disrupting compounds reduce the fertility, hatching success, impair the immune system and advance the cancer incidence in wildlife species of aquatic organisms [1-7]. The nature and synthetic steroid hormones are detected in the aquatic environments, which can impair the normal endocrine functions of aquatic organisms [8-13]. Recent studies have demonstrated the natural estrone (E1), estrogens E2, estriol (E3) and estrogen 17- $\alpha$-ethynylestradiol (EE2) present in the surface waters [14-21]. However, the adverse effects of progesterone on aquatic organisms have not been studied yet.

The zebrafish and human genomes share about $70 \%$ conserved syntenic fragments and many homologous genes in zebrafish and human show the similar functions and structures [22-25]. These results provide promising perspective using zebrafish for environmental risk assessment, which can be applied for further researches on humans.

Therefore, we aimed to evaluate the effect of progesterone on the reproduction of zebrafish. We measured the concentrations of hormones both in male and female zebrafish to examine the effect of progesterone on the endocrine functions. Our results showed that progesterone adversely impaired zebrafish reproduction in a dose-dependent manner. 


\section{Materials and methods}

\section{Chemicals}

Progesterone was purchased from Sigma-aldrich (P0130-25G). Stock solutions of $0.1,1$, and $10 \mathrm{mg} / \mathrm{ml}$ were prepared in ethanol and stored at $-20{ }^{\circ} \mathrm{C}$. The stock solutions were diluted with distilled water to the work concentrations of $1,10,100$ and $1000 \mathrm{ng} / \mathrm{L}$ in the exposure system. All the other reagents were of analytical grade.

\section{Fish husbandry}

Adult six-month age zebrafish were maintained in charcoal-filtered water (PH 7.0) at $28{ }^{\circ} \mathrm{C}$ with a $14: 10$ light/dark cycle. The fish were fed a combination of dry flake food (Tetra brand, USA) and live brine shrimp.

\section{Drug treatment}

Ten male and female fish were housed in 50-L glass tanks with $30 \mathrm{~L}$ water. Three replicate ranks were used for each group. During the 10-day exposure period, the zebrafish were exposed to nominal concentrations of progesterone $(0$, 1, 10, 100 and $1000 \mathrm{ng} / \mathrm{L})$, and water was changed daily. The embryos were collected daily and recorded. The zebrafish were raised in accordance with guidelines from the Institutional Animal Care and Use Committee (IACUC) of Huazhong University of Science and Technology. 


\section{Hormone measurement}

The blood samples were collected after the progesterone exposure. Plasma extraction and the measurement of sex hormone concentrations were performed as described previously [26]. Briefly, $20 \mu \mathrm{l}$ plasma were diluted to $500 \mu \mathrm{l}$ Milli-Q water (Millipore) and extracted with $2 \mathrm{ml}$ ethyl ether twice to collect the ether phase. The concentration of E2, T and 11-KT were detected according to the manufacturers' instructions (Cayman Chemical Company).

\section{Statistical analysis}

Differences between the control and exposure groups were evaluated by one-way analysis of variance (ANOVA) followed by Tukey's test. $\mathrm{P}<0.05$ was considered statistically significant.

\section{Results}

\section{Progesterone exposure decreased the egg productions of zebrafish}

Progesterone exposure had no obvious effect on the mortality in all groups during the 10-days treatment. There were no overt differences in the hatching and survival rates between each group, and the malformation rates were similar to the control group (Data not shown). 
Embryos production was consistent in each group during the exposure period, the lower concentrations of progesterone (1 and $10 \mathrm{ng} / \mathrm{L}$ ) appeared no significant impairment to the fish reproduction. When exposed to 100 and 1000 $\mathrm{ng} / \mathrm{L}$ of progesterone, female zebrafish produced fewer embryos compared to the non-exposed control group (Figure 1).

\section{Progesterone treatment reduced the sex hormone levels in zebrafish}

The plasma E2 levels in the female fish were significantly diminished in the 100 and $1000 \mathrm{ng} / \mathrm{L}$ of progesterone-treated group (Figure 2). Meanwhile, the $\mathrm{T}$ contents were significantly reduced in the $1000 \mathrm{ng} / \mathrm{L}$ of progesterone-exposed group (Figure 3). In the male fish, the $11-\mathrm{KT}$ concentrations were significantly decreased when exposed to the 100 and $1000 \mathrm{ng} / \mathrm{L}$ of progesterone (Figure 4).

\section{Discussion}

Recently, several studies report that natural progesterone may result in endocrine disruption and affect the reproductive system in fish [4, 27-33]. However, the toxicological effects of the progesterone on zebrafish have not been evaluated yet. In this study, our results showed that exposure to progesterone could impair zebrafish reproduction in a short period of time. We 
also found that the E2 and T levels in female fish and the 11-KT levels in male fish were significantly reduced when treated with progesterone.

Previous studies have demonstrated that progestins have no effect on embryonic development (hatching and survival) [33-36]. Our data are consistent with those previous findings, suggesting that progestins have no obviously acute toxicity to fish eggs. Thus far, the underlying mechanisms of the inhibition of progestins on fish productive system remain unknown. Progestins might mediate the reproductive signaling through progesterone receptors, which might play important roles in the fish.

Our results indicated that exposure to environmental concentrations of progesterone could interrupt the reproductive system in zebrafish. Our findings will be useful to predict the environmental health effects of progesterone on the fish species. 


\section{References}

1. Colborn, T., F.S. Vom Saal, and A.M. Soto, Developmental effects of endocrinedisrupting chemicals in wildlife and humans. Environmental health perspectives, 1993.101(5): p. 378.

2. $\quad$ Crisp, T.M., et al., Environmental endocrine disruption: an effects assessment and analysis. Environmental health perspectives, 1998. 106(Suppl 1): p. 11.

3. Diamanti-Kandarakis, E., et al., Endocrine-disrupting chemicals: an Endocrine Society scientific statement. Endocrine reviews, 2009. 30(4): p. 293-342.

4. $\quad$ Vandenberg, L.N., et al., Hormones and endocrine-disrupting chemicals: lowdose effects and nonmonotonic dose responses. Endocrine reviews, 2012. 33(3): p. 378-455.

5. Burkhardt-Holm, P., Endocrine disruptors and water quality: a state-of-the-art review. International Journal of Water Resources Development, 2010. 26(3): p. 477-493.

6. $\quad$ Zhong, L., et al., Investigation of effect of $17 \alpha$-ethinylestradiol on vigilin expression using an isolated recombinant antibody. Aquatic toxicology, 2014. 156: p. 1-9.

7. Song, G., et al., Effective gene trapping mediated by Sleeping Beauty transposon. PloS one, 2012. 7(8): p. e44123.

8. Khetan, S.K. and T.J. Collins, Human pharmaceuticals in the aquatic environment: a challenge to green chemistry. Chemical reviews, 2007. 107(6): p. 2319-2364.

9. Porte, C., et al., Endocrine disruptors in marine organisms: approaches and perspectives. Comparative Biochemistry and Physiology Part C: Toxicology \& Pharmacology, 2006. 143(3): p. 303-315.

10. Sumpter, J.P., Endocrine disrupters in the aquatic environment: an overview. CLEAN-Soil, Air, Water, 2005. 33(1): p. 9-16.

11. Kloas, W., et al., Endocrine disruption in aquatic vertebrates. Annals of the New York Academy of Sciences, 2009. 1163(1): p. 187-200.

12. Zhai, G., et al., Sept6 is required for ciliogenesis in Kupffer's vesicle, the pronephros, and the neural tube during early embryonic development. Molecular and cellular biology, 2014. 34(7): p. 1310-1321.

13. Gu, Q., et al., Genetic ablation of solute carrier family 7a3a leads to hepatic steatosis in zebrafish during fasting. Hepatology, 2014. 60(6): p. 1929-1941.

14. Puma, G.L., et al., Photocatalytic oxidation of multicomponent mixtures of estrogens (estrone (E1), 17 $\beta$-estradiol (E2), 17 $\alpha$-ethynylestradiol (EE2) and estriol (E3)) under UVA and UVC radiation: photon absorption, quantum yields and rate constants independent of photon absorption. Applied Catalysis B: Environmental, 2010.99(3): p. 388-397.

15. Van den Belt, K., et al., Effects of ethynylestradiol on the reproductive physiology in zebrafish (Danio rerio): time dependency and reversibility. Environmental toxicology and chemistry, 2002. 21(4): p. 767-775.

16. Czajka, C.P. and K.L. Londry, Anaerobic biotransformation of estrogens. Science of the total environment, 2006. 367(2): p. 932-941. 
17. Hutchins, S.R., et al., Analysis of lagoon samples from different concentrated animal feeding operations for estrogens and estrogen conjugates.

Environmental science \& technology, 2007. 41(3): p. 738-744.

18. Caldwell, D.J., et al., Derivation of an aquatic predicted no-effect concentration for the synthetic hormone, $17 \alpha$-ethinyl estradiol. Environmental science \& technology, 2008. 42(19): p. 7046-7054.

19. Bradley, P.M., et al., Biodegradation of $17 \beta$-estradiol, estrone and testosterone in stream sediments. Environmental science \& technology, 2009. 43(6): p. 1902-1910.

20. Gu, Q., et al., Generation and characterization of a transgenic zebrafish expressing the reverse tetracycline transactivator. Journal of Genetics and Genomics, 2013. 40(10): p. 523-531.

21. Yang, X., et al., Nucleoporin 62-like protein activates canonical Wnt signaling through facilitating the nuclear import of $\beta$-catenin in zebrafish. Molecular and cellular biology, 2015. 35(7): p. 1110-1124.

22. Postlethwait, J.H., et al., Zebrafish comparative genomics and the origins of vertebrate chromosomes. Genome research, 2000.10(12): p. 1890-1902.

23. Howe, K., et al., The zebrafish reference genome sequence and its relationship to the human genome. Nature, 2013. 496(7446): p. 498-503.

24. Stein, C., et al., Conservation and divergence of gene families encoding components of innate immune response systems in zebrafish. Genome biology, 2007. 8(11): p. R251.

25. Navratilova, P., et al., Systematic human/zebrafish comparative identification of cis-regulatory activity around vertebrate developmental transcription factor genes. Developmental biology, 2009. 327(2): p. 526-540.

26. Guillette Jr, L.J., et al., Developmental abnormalities of the gonad and abnormal sex hormone concentrations in juvenile alligators from contaminated and control lakes in Florida. Environmental health perspectives, 1994. 102(8): p. 680.

27. Runnalls, T.J., et al., Several synthetic progestins with different potencies adversely affect reproduction of fish. Environmental science \& technology, 2013.47(4): p. 2077-2084.

28. Gore, A., et al., EDC-2: the endocrine society's second scientific statement on endocrine-disrupting chemicals. Endocrine reviews, 2015. 36(6): p. E1-E150.

29. Milla, S., S. Depiereux, and P. Kestemont, The effects of estrogenic and androgenic endocrine disruptors on the immune system of fish: a review. Ecotoxicology, 2011. 20(2): p. 305-319.

30. Casals-Casas, C. and B. Desvergne, Endocrine disruptors: from endocrine to metabolic disruption. Annual review of physiology, 2011. 73: p. 135-162.

31. Frye, C., et al., Endocrine disrupters: a review of some sources, effects, and mechanisms of actions on behaviour and neuroendocrine systems. Journal of neuroendocrinology, 2012. 24(1): p. 144-159.

32. Balabanič, D., M. Rupnik, and A.K. Klemenčič, Negative impact of endocrinedisrupting compounds on human reproductive health. Reproduction, Fertility and Development, 2011. 23(3): p. 403-416. 
33. Zama, A.M. and M. Uzumcu, Epigenetic effects of endocrine-disrupting chemicals on female reproduction: an ovarian perspective. Frontiers in neuroendocrinology, 2010.31(4): p. 420-439.

34. Inskeep, E., Preovulatory, postovulatory, and postmaternal recognition effects of concentrations of progesterone on embryonic survival in the cow. Journal of animal science, 2004. 82(13_suppl): p. E24-E39.

35. Clemente, M., et al., Progesterone and conceptus elongation in cattle: a direct effect on the embryo or an indirect effect via the endometrium? Reproduction, 2009.138(3): p. 507-517.

36. Morris, D. and M. Diskin, Effect of progesterone on embryo survival. Animal: an international journal of animal bioscience, 2008. 2(8): p. 1112. 
Figures

Figure 1. Exposed to progesterone impaired reproduction in zebrafish.

Figure 1

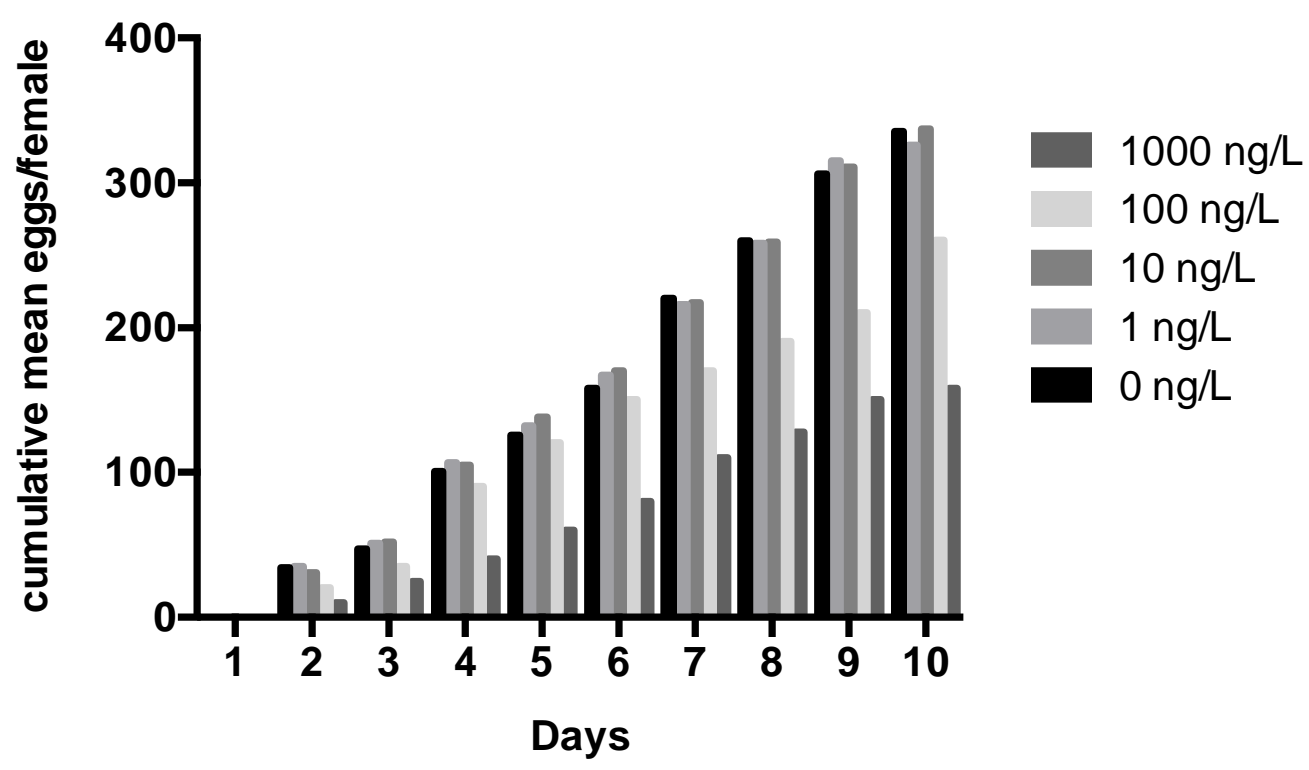

Figure 2. Exposed to progesterone decreased the estradiol (E2) concentrations in female zebrafish.

Figure 2

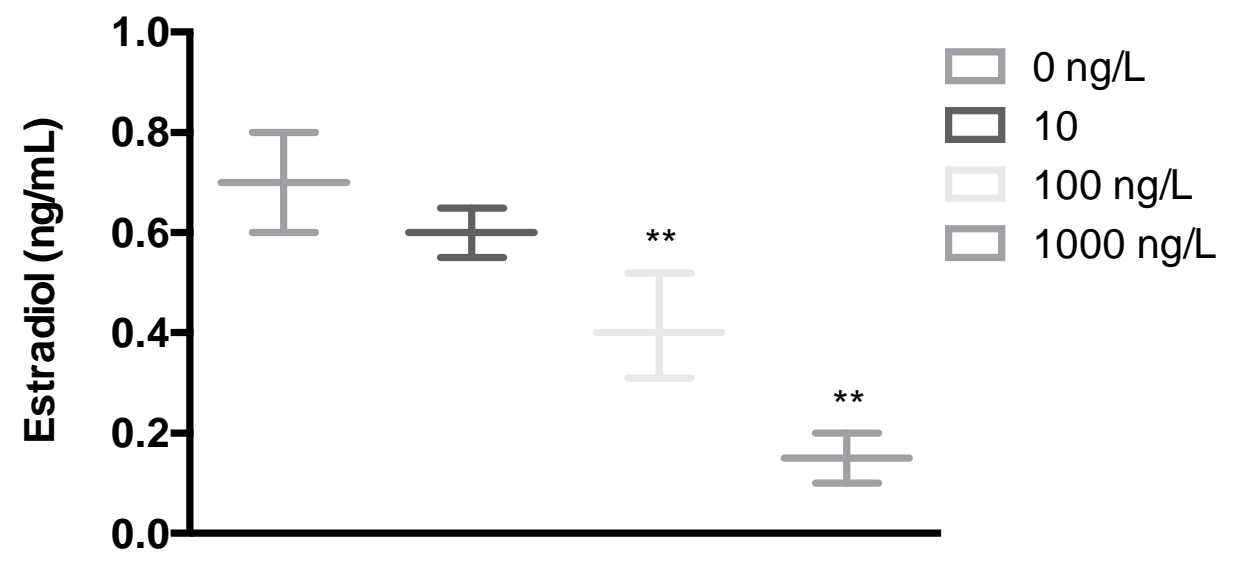


Figure 3. Exposed to progesterone decreased the testosterone ( $T$ ) concentrations in female zebrafish.

Figure 3

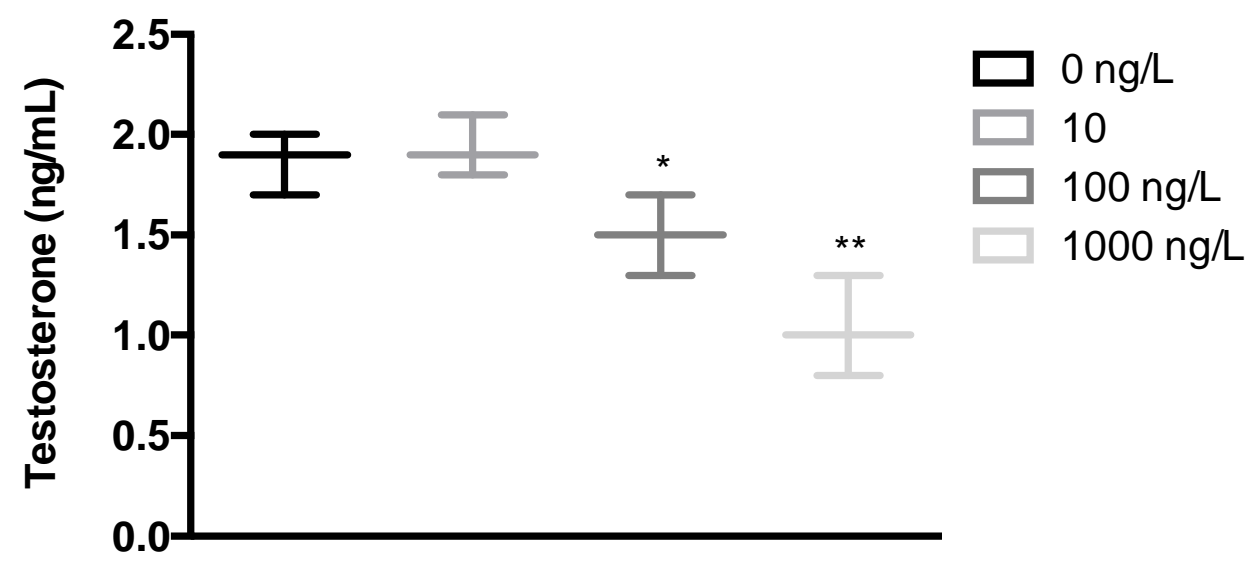

Figure 4. Exposed to progesterone decreased the 11-keto testosterone (11-KT) concentrations in male zebrafish.

Figure 4

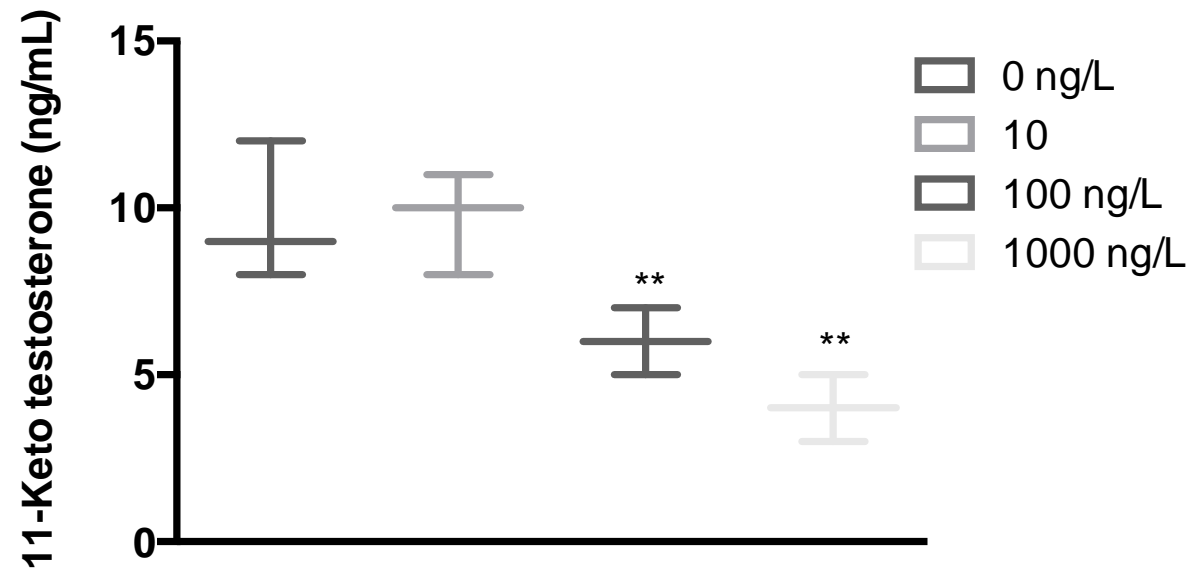

